\title{
Heat Shock Factor 1-Deficient Mice Exhibit Decreased Recovery of Hearing Following Noise Overstimulation
}

\author{
Damon A. Fairfield, ${ }^{1,2}$ Margaret I. Lomax, ${ }^{1,2}$ Gary A. Dootz, ${ }^{1}$ Shu Chen, ${ }^{3}$ \\ Andrzej T. Galecki, ${ }^{3}$ Ivor J. Benjamin, ${ }^{4}$ David F. Dolan, ${ }^{1}$ and \\ Richard A. Altschuler ${ }^{1,2 \star}$ \\ ${ }^{1}$ Kresge Hearing Research Institute, Department of Otolaryngology/Head Neck Surgery, \\ University of Michigan, Ann Arbor, Michigan \\ ${ }^{2}$ Department of Cell and Developmental Biology, University of Michigan, Ann Arbor, Michigan \\ ${ }^{3}$ Institute of Gerontology, University of Michigan, Ann Arbor, Michigan \\ ${ }^{4}$ Department of Internal Medicine, Division of Cardiology, University of Utah, Salt Lake City, Utah
}

Heat shock proteins (Hsps) can enhance cell survival in response to stress. Heat shock factor 1 (Hsf1) is the major transcription factor that regulates stress-inducible $H s p$ expression. We previously demonstrated the presence of Hsf1 in the rodent cochlea and also demonstrated that a heat shock known to precondition the cochlea against noise trauma results in Hsf1 activation in the rodent cochlea. In the present study, we used an Hsf1-deficient $\left(\mathrm{Hsf1}^{--}\right)$mouse model to determine whether eliminating the Hsf1-dependent stress pathway would influence hearing loss and/or recovery from a moderate-intensity noise. $\mathrm{Hsf1^{-/- }}$ mice and their normal littermates $\left(\mathrm{Hsf1}^{+/+}\right)$were exposed to a $98-\mathrm{dB}$, broadband $(2-20 \mathrm{kHz})$ noise for $2 \mathrm{hr}$, and auditory brainstem response thresholds were measured at three frequencies $(4,12$, and $20 \mathrm{kHz}) 3 \mathrm{hr}, 3$ days, and 2 weeks after noise. $\mathrm{Hsf1}^{-1-}$ mice had greater hearing loss than $\mathrm{Hsfl}^{+/+}$mice, with significant differences in recovery observed at all frequencies tested by 2 weeks after noise. Increased outer hair cell loss was also observed in $\mathrm{Hsf1}^{-/}$mice following noise. These studies provide evidence for the importance of Hsf1 in cochlear protection, recovery, and/or repair following noise overstimulation.

๑) 2005 Wiley-Liss, Inc.

Key words: stress pathways; protection; survival; recovery; cochlea

Cells respond to stress by activating a variety of molecular pathways, some of which result in enhanced cell survival, with others leading to cell death. One of the best characterized families of protective proteins is the heat shock proteins (Hsps). Under normal conditions, Hsps are involved in a variety of cellular functions. After stress, Hsp expression is up-regulated, resulting in increased cellular protection and survival (Morimoto et al., 1997). In the rodent cochlea, Hsp70 is up-regulated following hyperthermia (Dechesne et al., 1992; Yoshida et al., 1999), ischemia (Myers et al., 1992), noise overstimulation (Lim et al., 1993), and cisplatin ototoxicity (Oh et al., 2000). Prior induction of the stress response, by using a mild stress followed by recovery, provides cellular protection against a subsequent, more damaging stress, if the second stress is given at a time when induced Hsp levels are highest (Landry et al., 1989; Hutter et al., 1994), a phenomenon known as "preconditioning" or "acquired thermotolerance." Mice preconditioned by a heat shock that upregulates Hsp70 are protected against a subsequent damaging noise exposure if the noise is given at a time when Hsp70 levels are maximal (Yoshida et al., 1999).

Heat shock factor 1 (Hsfl) is one of the transcription factors responsible for regulating stress-induced Hsp expression. Under normal conditions, Hsf1 is maintained in an inactive monomeric state. In response to stress, monomeric Hsf1 undergoes trimerization and an increase in phosphorylation, resulting in Hsf1 activation and the transcription of its target genes (Morimoto et al., 1997). Overexpression of constitutively activated Hsf1 in vitro in mammalian cells results in Hsp up-regulation and increased cellular protection against heat shock and ischemia (Wagstaff et al., 1998; Xia et al., 1999). In contrast, although elimination of Hsf1 does not affect basal levels of Hsp expression, its absence either in vitro in mouse embryonic fibroblasts (MEFs; McMillan et al., 1998; Luft et al., 2001) or in vivo in $H_{s f 1^{-/-}}$mice (Xiao et al., 1999;

Contract grant sponsor: NIH; Contract grant number: PO1 DCO2687; Contract grant number: P-30 DCO5188; Contract grant sponsor: NIH/ NIDCD; Contract grant number: T32 DC00011.

*Correspondence to: Dr. Richard A. Altschuler, KHRI, Department of Otolaryngology, The University of Michigan, 1301 East Ann Street, Ann Arbor, MI 48109-0506. E-mail: shuler@umich.edu

Received 2 September 2004; Revised 6 December 2004; Accepted 8 December 2004

Published online 10 June 2005 in Wiley InterScience (www. interscience.wiley.com). DOI: 10.1002/jnr.20417 
Zhang et al., 2002) results in the inability to up-regulate stress-inducible Hsps following heat shock, leading to enhanced cell death (via apoptosis) and the prevention of acquired thermotolerance.

We previously demonstrated the presence of Hsf1 in the outer and inner hair cells of the organ of Corti, in the stria vascularis, and in the spiral ganglion cells of the modiolus of the normal rat and mouse cochlea (Fairfield et al., 2002). We also demonstrated that the heat shock shown to precondition the cochlea against noise trauma (Yoshida et al., 1999) results in Hsf1 activation in the rodent cochlea (Fairfield et al., 2002). The development of an Hsf1-deficient mouse model (Xiao et al., 1999) allows a more specific examination of the role of the Hsf1dependent stress pathway in the cochlea. $H s f 1^{-1-}$ mice exhibit normal development of all tissues examined in both embryos and adult mice (Xiao et al., 1999); however, $H s f 1^{-1-}$ mice exhibit prenatal lethality to various extents, depending on the genetic background. This prenatal lethality is due to defects in the spongiotrophoblast layer of the choroallantoic placenta by late midgestation (Xiao et al., 1999). Hsf1 ${ }^{-\prime-}$ mice of both sexes also exhibit growth retardation (Xiao et al., 1999). Male $H s f 1^{-/-}$mice exhibit normal fertility, whereas female $H s f 1^{-1-}$ mice are completely infertile (Xiao et al., 1999; Christians et al., 2000). $H s f 1^{-/-}$mice also exhibit increased mortality in response to direct antigenic challenge as a result of the overexpression of the proinflammatory cytokine tumor necrosis factor- $\alpha$ (TNF- $\alpha)$, which is normally negatively regulated by Hsf1 (Xiao et al., 1999). Here, we use this wellcharacterized Hsf1-deficient mouse model to investigate the role of Hsf1 in cochlear protection and recovery following a moderate-intensity noise.

\section{MATERIALS AND METHODS}

\section{Animals}

Young, 8-10-week-old Hsf1-deficient mice as well as $\mathrm{BALB} / \mathrm{c}$ mice (the background strain on which the Hsf1deficient mice were maintained) were used in this study. All animals were treated following the "Anesthesia and recoverystandard operating procedures" in accordance with the policies of the University Laboratory Animal Medicine Department of the University of Michigan.

\section{Hsf1-Deficient Mice: Breeding}

Hsf1-deficient mice were generated by replacing a $1.8-\mathrm{kb}$ region of the $H_{s} f 1$ gene with a neomycin $(N E O)$ resistance expression cassette via homologous recombination (McMillan et al., 1998; Xiao et al., 1999). This results in the deletion of $\sim 80 \%$ of the DNA binding domain and the elimination of the three leucine zippers that make up the trimerization domain (Xiao et al., 1999), resulting in a truncated $H s f 1$ mRNA (McMillan et al., 1998) and the complete absence of Hsf1 protein in homozygotes (McMillan et al., 1998; Xiao et al., 1999). These Hsf1 knockout (KO) mice were generated in the mixed genetic background $\mathrm{C}$, 129X1 (129X1/SvJ × BALB/c; McMillan et al., 1998) and were maintained by brother-sister matings.

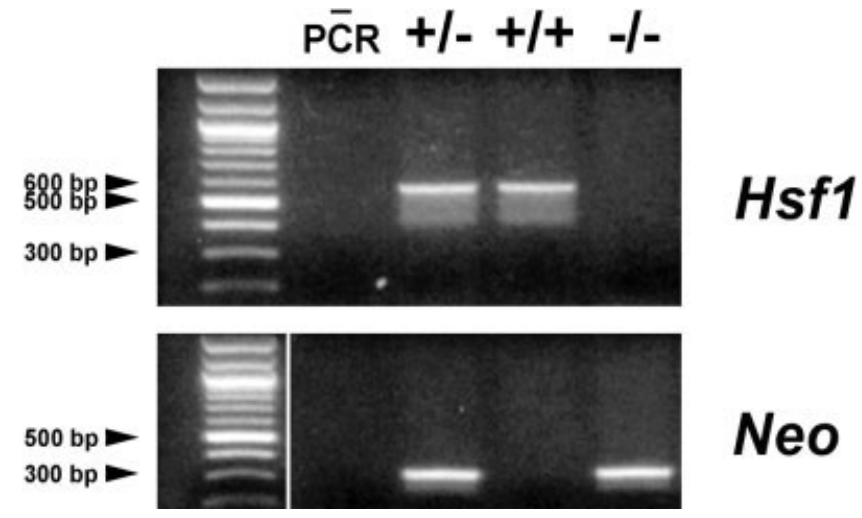

Fig. 1. Identification of $H_{s f 1^{+/+}}$and $H_{s f 1^{-/-}}$mice. Hsf1 null mice were genotyped for our studies by PCR amplification of genomic DNA using gene specific primers for $H s f 1$ and NEO. The upper panel used primers for $H s f 1$, which yield a 562-bp product from the wildtype $H_{s f 1}$ gene. The lower panel used primers for NEO, which yield a 377-bp product. $-\mathrm{PCR}$, PCR control with no DNA template; $+/+$, $+/-,-/-$, genotype at the Hsf1 locus.

\section{Hsf1-Deficient Mice: Genotyping}

Genomic DNA was isolated from tail biopsies of weanling Hsf1 mice by using a DNeasy Tissue Kit (Qiagen, Valencia, CA). Genomic DNA was amplified by PCR using primers specific for either the mouse Hsf1 gene (Genbank accession No. AF059275) or the NEO expression cassette (Genbank accession No. AF090454), as described previously (McMillan et al., 1998; Xiao et al., 1999). For Hsf1, the upstream primer is complementary to intron 4; the downstream primer is complementary to intron 6: upstream primer 5'-AGACCTGTCCTGTGTGCCTAGC-3' (nt 6,3466,367), downstream primer 5'-CAGTTCAACTGCCTACACAGACC-3' (nt 6,910-6,888). For NEO, primers were designed as follows: upstream primer $5^{\prime}$-AGGACATAGCGTTGGCTACCCGTG-3' (nt 2,990-3,013), downstream primer $5^{\prime}$-GCCTGCTATTGTCTTCCCAATCC-3' (nt $3,364-3,342)$. PCRs were performed on $2 \mu l$ of genomic DNA using Ampli-Taq Gold (Applied Biosystems, Foster City, CA) and were incubated at $95^{\circ} \mathrm{C}$ for $10 \mathrm{~min}$ to activate the enzyme. Thermocycling conditions were: $94^{\circ} \mathrm{C}$ for $45 \mathrm{sec}, 63^{\circ} \mathrm{C}$ for $45 \mathrm{sec}, 72^{\circ} \mathrm{C}$ for $1 \mathrm{~min}$, for 35 cycles. PCR products were separated by electrophoresis on a $1.2 \%$ agarose gel and visualized by ethidium bromide staining. Molecular weight was determined with a 100-bp DNA ladder (New England Biolabs, Beverly, MA). Wild-type mice with two copies of the $H_{s f 1}$ gene $\left(H_{s} f 1^{+/+}\right)$yield a $562-$ bp PCR product. Homozygous null mice that lack the $H_{s f 1}$ gene but contain the NEO gene $\left(\mathrm{Hsf1}^{-/}\right)$yield a $377-\mathrm{bp}$ PCR product. Heterozygotes $\left(\mathrm{Hsf}^{+1^{+-}}\right)$contain one copy of each gene and therefore have both PCR products (Fig. 1). The 562-bp and 377-bp PCR products generated by the Hsf1 and NEO primers were isolated using a QIAquick Gel Extraction Kit (Qiagen, Valencia, CA), and their identity was confirmed by DNA sequencing (University of Michigan DNA Sequencing Core, Ann Arbor, MI). 


\section{Noise Exposure}

$H_{s f} 1^{+/+}$and $H_{s f} 1^{-/-}$mice were placed in individual wire mesh cages that were positioned on a rotation table (1 rotation/ $30 \mathrm{sec}$ ) in a lighted and ventilated sound-exposure booth. Animals were exposed, unanesthetized, to a broadband $(2-20 \mathrm{kHz})$ noise at $98 \mathrm{~dB}$ SPL for $2 \mathrm{hr}$. The sound chamber was fitted with speakers (model $2450 \mathrm{H}$; JBL) driven by a noise generator (ME $60 \mu$ graphic equalizer; Rane) and power amplifier (HCA100 high-current power amplifier; Parasound Products). To assess stimulus uniformity, sound levels were calibrated and measured (type 2203 precision sound level meter, type 4134 microphone; Brüel and Kjaer Instruments) at multiple locations within the sound booth by using a fast Fourier transform network analyzer with a linear scale.

\section{Auditory Brainstem Response}

The normal hearing baseline auditory brainstem responses (ABRs) were compared among $H_{s} f 1^{+/+}, H_{s} f 1^{-/-}$, and BALB/c mice (Jackson Laboratories, Bar Harbor, MA), to determine whether $H_{s} f^{-/-}$mice had normal hearing. For the ABR measurements, the animals were anesthetized with an intraperitoneal injection of xylazine $(7 \mathrm{mg} / \mathrm{kg})$, ketamine $(65 \mathrm{mg} / \mathrm{kg})$, and acepromizine $(2 \mathrm{mg} / \mathrm{kg})$. Active needle electrodes were placed subcutaneously below the tested ear (negative reference); an additional active electrode was placed at the vertex of the head (positive reference). The ground electrode was a needle electrode inserted subcutaneously below the contralateral ear. The sound stimulus consisted of a 15 -msec tone burst, with a rise-fall time of $1 \mathrm{msec}$. The sound intensity was initially varied in $10-\mathrm{dB}$ steps, then in 5-dB steps near threshold. One thousand twentyeight tone presentations were delivered at 10 per second, averaged to obtain a waveform with a Tucker-Davis data acquisition system (System 2). Hearing thresholds at 4, 12, and $20 \mathrm{kHz}$ were defined as the lowest intensity of stimulation that yielded a repeatable waveform with an identifiable peak in the ABR waveform.

For the studies examining the effect of noise on hearing, the thresholds in the left ear of each animal were determined with pure-tone ABRs measured at 4, 12, and $20 \mathrm{kHz}$ at least 1 day prior to the noise exposure (baseline) and then $3 \mathrm{hr}$, 3 days, and 2 weeks after noise. The Hsf1 KO mice used in this study were generated in the mixed genetic background $\mathrm{C}$, 129X1 (129X1/SvJ × BALB/c; McMillan et al., 1998), so this resulted in increased variability in their threshold shifts following noise compared with inbred mouse strains. To decrease variability in the effect of noise, a threshold shift of at least $50 \mathrm{~dB}$ at $12 \mathrm{kHz}, 3 \mathrm{hr}$ after noise, was set as a criterion for inclusion in the study. This level was chosen based on preliminary studies showing a biphasic response, with the majority of animals showing such a threshold shift and a smaller number showing shifts of 30 $\mathrm{dB}$ or less. This biphasic response was comparable in both $H_{s} f^{-/-}$and $H_{s} f 1^{+/+}$mice.

\section{Statistical Analysis}

The goal of the analysis was to examine the difference of the threshold shift between genotype $H_{s} f 1^{+/+}$and genotype $H_{s} \mathrm{f}^{-/-}$mice at different times following the noise exposure (e.g., $3 \mathrm{hr}, 3$ days, and 2 weeks) and at different frequencies (e.g., 4,12 , and $20 \mathrm{kHz}$ ) at which ABRs were measured. To take into account repeated ABR measures in the data, we fitted linear mixed-effect models by using the SAS/MIXED procedure (Proc Mixed in SAS version 9.1; SAS Institute, Cary, NC). In the analysis we used the following qualitative covariates: genotype $\left(H s f 1^{+/+}\right.$vs. $\left.H s f 1^{-/}\right)$, time following the noise exposure and frequency, and their interactions. In the process of building a model for the data, we also took into account heterogeneity in the covariance structure for different mouse genotypes. To select the best model, we compared pairs of nested models using likelihood ratio based tests. Specific hypotheses involving regression parameters were tested within the best model by likelihood ratio test. A $P$ value less than 0.05 was considered to be statistically significant.

\section{Morphology}

Cochleae from three $H_{s f} 1^{+/+}$and three $H_{s f} 1^{-/-}$mice were examined using phalloidin-stained surface preparations to determine whether the morphology was normal. To compare morphology following noise overstimulation, phalloidin-stained surface preparations of cochleae from three noise-exposed and three untreated control mice were compared for both $\mathrm{H}_{s} \mathrm{f}^{+/+}$ and $H s f 1^{-1-}$ mice, 2 weeks after noise overstimulation. Mice were deeply anesthetized with a single dose of $35 \mathrm{mg} / \mathrm{kg} 35 \%$ chloral hydrate (Sigma, St. Louis, MO) injected intraperitoneally (i.p.) and perfused transcardially with cold phosphate buffer, followed by fixative containing $4 \%$ paraformaldehyde in phosphate buffer. Temporal bones were removed, and cochleae received an additional intrascalar fixation with the same fixative through the round window, followed by a $2-16-\mathrm{hr}$ immersion at $4^{\circ} \mathrm{C}$. Cochleae were then rinsed in phosphate-buffered saline (PBS). For surface preparations, the otic capsule was partially decalcified in $3 \%$ EDTA at $4{ }^{\circ} \mathrm{C}$ for 1 day, and the otic capsule was then removed, followed by removal of stria vascularis, tectorial membrane, and Reissner's membrane. The remaining organ of Corti spiraling around the modiolus was stained as a whole preparation. Whole mounts were placed in $0.3 \%$ Triton $\mathrm{X}-100$ for $10 \mathrm{~min}$ at room temperature and then rinsed in PBS. Whole mounts were incubated with rhodamine-labeled phalloidin (Molecular Probes, Eugene, OR) diluted 1/100 in PBS for $1 \mathrm{hr}$ in the dark. Whole mounts were rinsed in PBS and further dissected into surface preparations of the organ of Corti, mounted on slides, and coverslipped with fluoromount. Surface preparations were examined under a fluorescence microscope (Zeiss, Jena, Germany), and comparable regions from the basal and apical turns were compared for the presence of inner and outer hairs vs. scarring. Representative images were obtained with a Nikon PCM2000 digital camera (Nikon, Sunnyvale, CA) and MetaMorph 6.1 software (Universal Imaging Corp., Downington, PA).

\section{RESULTS}

\section{Hsf1-Deficient Mice Exhibit Normal Hearing}

To determine whether elimination of the Hsf1regulated stress pathway affected normal auditory function, we measured the hearing sensitivity of Hsf1 null $\left(H_{s f} 1^{-\prime-}\right)$ mice, their wild-type littermates $\left(H_{s} f 1^{+/+}\right)$, and $\mathrm{BALB} / \mathrm{c}$ mice (the background strain) by measuring their baseline ABR (Fig. 2). No significant difference in thresh- 


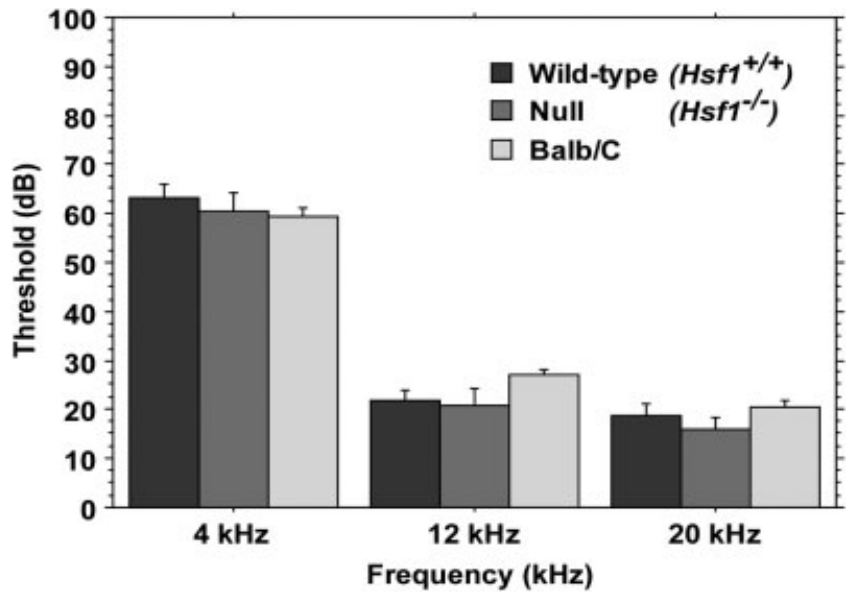

Fig. 2. $H_{s} f 1^{+/+}$and $H s f 1^{-/-}$mice exhibit normal hearing. Auditory brainstem responses (ABRs) were measured in $\mathrm{Hsf1}^{+/+}$and $\mathrm{Hsf1}^{-/-}$ mice and their BALB/c background strain (Jackson Laboratoriess) at 4, 12 , and $20 \mathrm{kHz}$ to assess baseline hearing. Error bars indicate \pm 1 SEM; $\mathrm{n}=19$ for $H_{s f} 1^{+/+}, \mathrm{n}=15$ for $H s f 1^{-/-}, \mathrm{n}=35$ for BALB/c.

old was observed among these three strains of mice, indicating that both Hsf1 wild-type and mutant mice have normal hearing. This result is consistent with the observation that there are no detectable morphological, microscopic, or histopathological abnormalities present in any of the soft or solid tissues that have been previously examined in $H s f 1^{-1-}$ embryos or adult mice (Xiao et al., 1999).

\section{$H s f 1^{-/-}$Mice Exhibit Decreased Cochlear Recovery After Noise}

$H s f 1^{-1-}$ mice exhibited significantly less recovery of hearing than $H_{s f 1} 1^{+/+}$mice. Hsf $1^{+/+}$mice showed a complete recovery of hearing by 3 days following noise. At $3 \mathrm{hr}$ following noise, all animals had greater than $50-\mathrm{dB}$ threshold shifts at 12 and $20 \mathrm{kHz}$. The $\mathrm{Hsf1}^{-1-}$ mice had significantly greater threshold shifts than the $\mathrm{Hs}_{s} \mathrm{1}^{+/+}$mice at 20 and $4 \mathrm{kHz}(P<0.05$; Fig. 3$)$. By 3 days following the noise, when $H_{s f} 1^{+/+}$mice had recovered their hearing (mean threshold shift close to zero), the $H_{s f 1^{-1-}}$ mice had significantly greater threshold shifts; $42.5 \mathrm{~dB}$ at $20 \mathrm{kHz}$ $(P<0.05)$ and $25 \mathrm{~dB}$ at $12 \mathrm{kHz}(P<0.05)$ with the $15-\mathrm{dB}$ change at $4 \mathrm{kHz}$ not significant (Fig. 3). At 2 weeks following noise, the hearing threshold in $\mathrm{Hsf}^{+/+}$mice remained normal, whereas $H s f 1^{-\prime-}$ mice still had significantly greater hearing loss $(P<0.05)$, now at all three frequencies tested, with a mean threshold shift of $25 \mathrm{~dB}$ at $20 \mathrm{kHz}, 20 \mathrm{~dB}$ at $12 \mathrm{kHz}$, and $15 \mathrm{~dB}$ at $4 \mathrm{kHz}$ (Fig. 3). No significant difference in threshold shift was observed between male and female $H_{s} f 1^{-1-}$ mice at any time point examined, nor was any significant difference seen that correlated with coat color (data not shown).

\section{$H s f 1^{-/-}$Mice Exhibit Outer Hair Cell Loss After Noise}

Both $\mathrm{Hsf1}^{+/+}$(Fig. 4A) and $\mathrm{Hsf1}^{-/-}$(Fig. 4C) mice exhibited a normal complement of inner and outer hair cells in phalloidin-stained surface preparations of the organ of Corti of cochleae that had not been noise exposed. At 2 weeks following noise overstimulation, no loss of outer or inner hair cells was observed in wild-type mice (Fig. 4B), which is consistent with their complete ABR threshold recovery from the noise exposure at this time. In contrast, in the $H_{s} f 1^{-1}$ mice, there was consistent outer hair cell loss at 2 weeks after noise (Fig. 4D), with a few outer hair cells lost in the second turn and regions of $50-75 \%$ outer hair cell loss in the basal turn (Fig. 4D). Whereas a quantitative assessment of hair cell loss was not made in this study, a qualitative appraisal suggested that there was more outer hair cell loss in the Hsf1 $1^{-1-}$ mice with the greatest amount of threshold shift, as might be expected.

\section{DISCUSSION}

Hsf1 is present in the organ of Corti, stria vascularis, and auditory nerve of the normal rodent cochlea (Fairfield et al., 2002). The pattern of Hsf1 expression directly correlates with that previously reported for other stress-responsive Hsps, such as Hsp70, in these tissues (Lim et al., 1993). Insofar as Hsf1 regulates the expression of the stress-inducible Hsps, these results suggested that Hsf1 might be involved in the process of cochlear protection. In the present study, we tested this hypothesis by assessing the ability of Hsf1-deficient mice to recover from a TTS noise exposure that does not cause PTS in wild-type mice.

Eliminating Hsf1 protein does not affect basal auditory function. There is no significant difference in hearing sensitivity between wild-type $\left(H s f 1^{+/+}\right)$, homozygous null $\left(H s f 1^{-1-}\right)$, and BALB/c mice, indicating that Hsf1 null mice have normal hearing thresholds. Hsf $1^{-1-}$ mice also exhibit normal cochlear morphology and a full complement of both outer and inner hair cells. This result is consistent with previous observations showing that $H s f 1^{-/-}$mice exhibit normal development of all tissues examined (Xiao et al., 1999). Similar results have recently been reported by Sugahara et al. (2003) for a different Hsf1-deficient mouse strain (Inouye et al., 2003) maintained on an ICR background.

$H s f 1^{-1}$ mice exhibit a significant loss of hearing following exposure to a moderate-intensity noise that in wild-type mice normally results in full recovery of hearing by 2 weeks after noise. $H_{s f 1^{-1-}}$ mice had a significantly higher average threshold shift than wild-type mice at all frequencies examined by 2 weeks after noise, with the magnitude of the PTS greatest at $20 \mathrm{kHz}>12 \mathrm{kHz}>$ $4 \mathrm{kHz} . H_{s f} 1^{-1-}$ mice, but not their wild-type littermates, exhibited moderate outer hair cell loss at all cochlear turns examined at 2 weeks after noise, with the most significant effects observed in the basal turn of the cochlea. This gradient is consistent with the observation that basal outer hair cells are more susceptible to stress-induced damage than apical outer hair cells, resulting from differences in the levels of the free radical scavenger glutathione (Sha et al., 2001). Similar results have recently been reported (Sugahara et al., 2003) for a different Hsf1-deficient mouse 

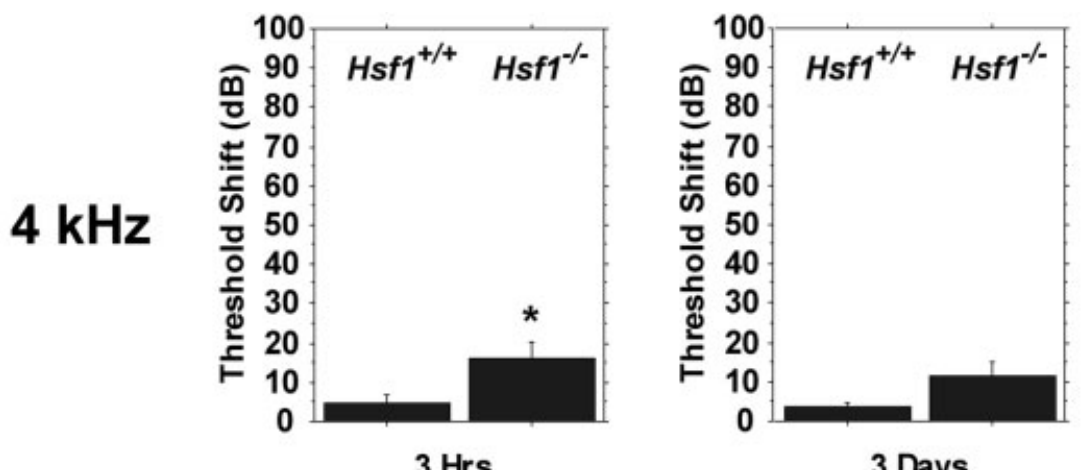

3 Days

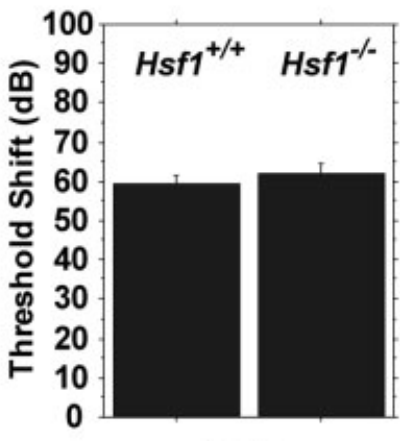

$3 \mathrm{Hrs}$

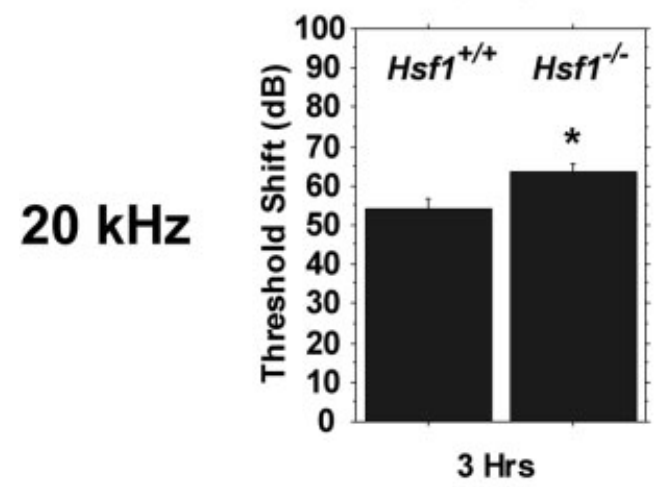

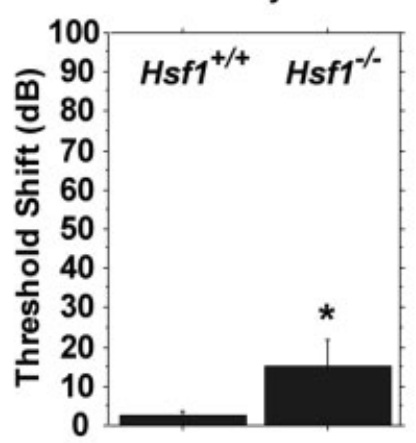

3 Days

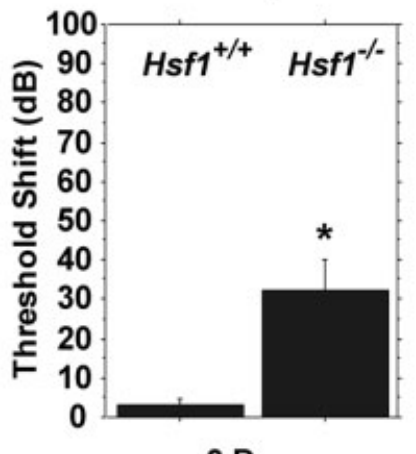

3 Days

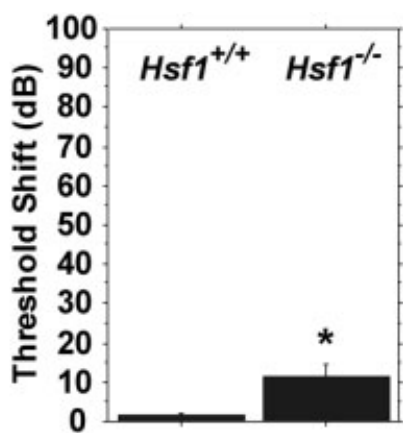

2 Wks

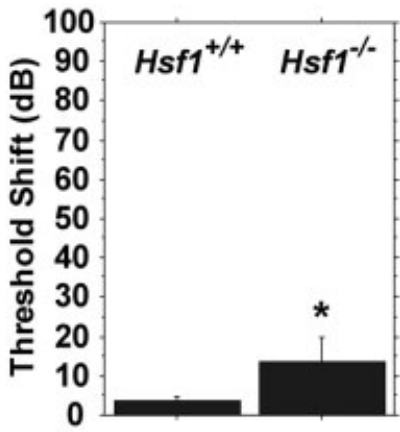

2 Wks

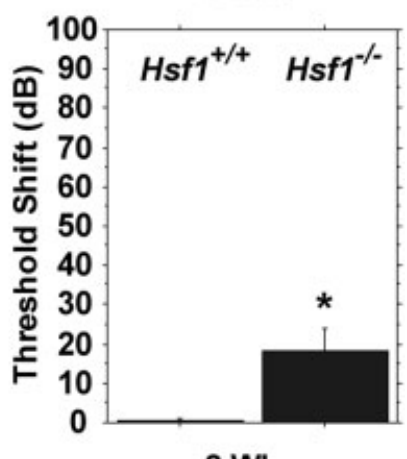

\section{Time after noise exposure}

Fig. 3. $H s f 1^{-/-}$mice exhibit decreased cochlear recovery following noise overstimulation. $H_{s f} 1^{+/+}$and $H s f 1^{-1-}$ mice were exposed to a $98-\mathrm{dB}$, broadband noise for $2 \mathrm{hr}$. Hearing sensitivity was determined at three time points after noise exposure: $3 \mathrm{hr}, 3$ days, and 2 weeks. For each time point, ABRs were measured at 4, 12, and $20 \mathrm{kHz}$. The average threshold shift for individual frequencies was compared between $\mathrm{Hsf1}_{\mathrm{f}}^{+/+}$and $\mathrm{Hsf1}^{-/-}$mice at each time point. Error bars indicate $\pm 1 \mathrm{SEM} ;{ }^{\star} P<.05 ; \mathrm{n}=13$ for $H_{s f} 1^{+/+}, \mathrm{n}=10$ for $H_{s f 1^{-/}}$. strain (Inouye et al., 2003), by using a noise-exposure paradigm designed to examine cochlear protection following traumatic stress, as opposed to the moderate-intensity noise used in our current study that allowed complete recovery by wild-type mice. In the Sugahara et al. study, $H s f 1^{-1-}$ mice were exposed to a damaging, high-intensity noise (130 dB SPL) for $1 \mathrm{hr}$, followed by recovery for $6 \mathrm{hr}$, a time at which Hsp70 levels are known to be maximally induced following noise in the rat cochlea (Lim et al., 1993). Mice were then exposed to a second high-intensity noise (130 dB SPL) for $10 \mathrm{hr}$. Consistent with our find- ings, Sugahara et al. (2003) observed a large loss (60\%) of outer hair cells in $\mathrm{Hsf1}^{-}$- mice at 7 days after noise, compared with a smaller loss $(20 \%)$ of outer hair cells in $H_{s} \mathrm{f}^{+/+}$mice. However, interestingly, although our study showed excellent correlation between hair cell loss and ABR threshold shifts, Sugahara et al. (2003) found no significant difference in the ABR threshold shift for noiseexposed $H_{s} f 1^{+/+}$vs. $H_{s} f 1^{-1-}$ mice. This may be a consequence of their different exposure conditions, which result in substantial damage to hair cells in both their $H_{s f} 1^{+/+}$ and $H s f 1^{-\prime-}$ mice. 


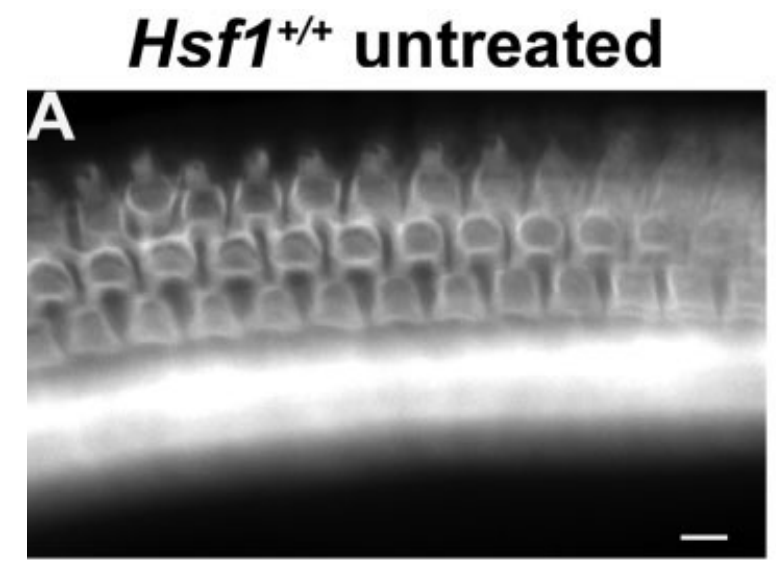

\section{$H_{s f 1}{ }^{+/+} 2$ wks after noise}

\section{Hsf1\% untreated}

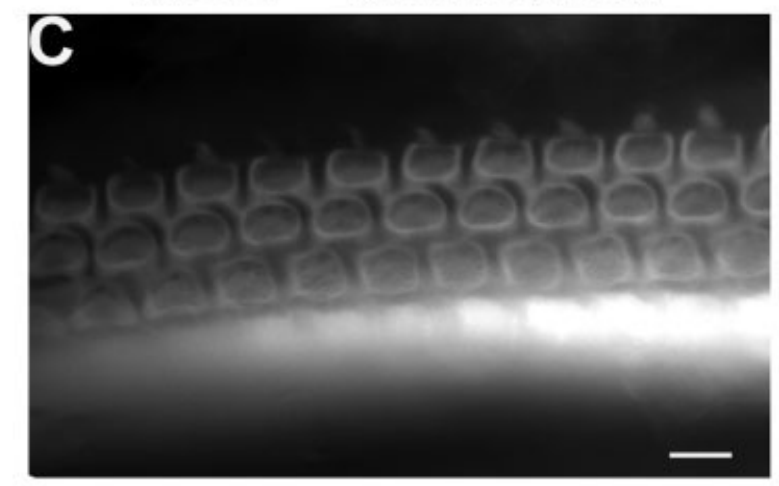

\section{Hsf1 $^{1 / 2}$ wks after noise}

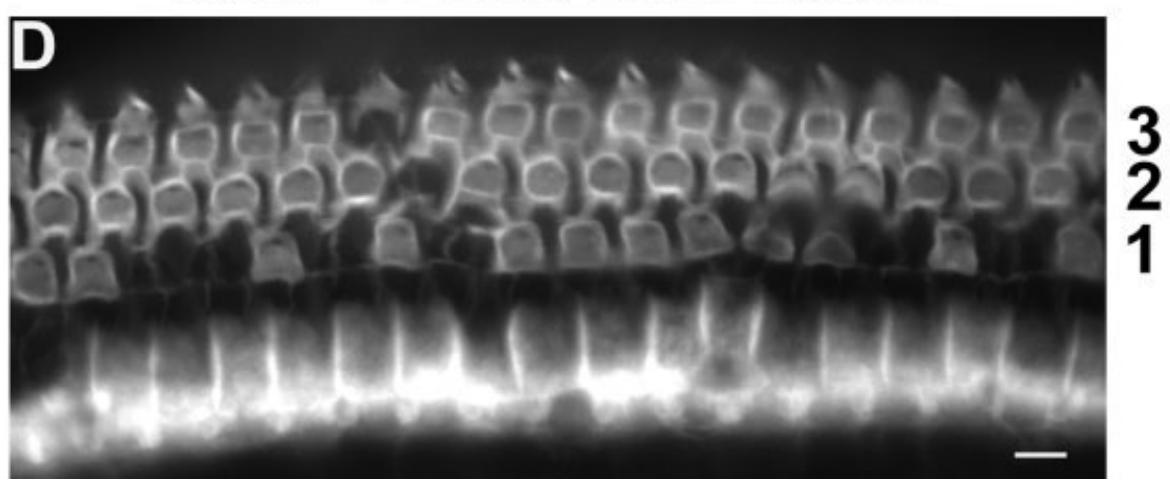

Fig. 4. $H_{s} \mathrm{f}^{-1-}$ mice exhibit increased outer hair cell loss following noise overstimulation. Cochlear hair cell survival was assessed by using rhodamine phalloidin to stain actin microfilaments in surface preparations of the organ of Corti from $\mathrm{Hsf1}^{+/+}$and $\mathrm{Hsf1}^{-/-}$mice. A: Representative phalloidin-stained surface preparation from the middle basal turn of an untreated control $\mathrm{Hsf1}^{+/+}$mouse cochlea, showing a normal complement of outer hair cells. B: Representative phalloidin-stained surface preparation from the middle basal turn of an $\mathrm{Hsf1}^{+/+}$mouse cochlea 2 weeks after noise, showing only minimal scattered outer hair cell loss. C: Representative phalloidin-stained surface preparation from the middle basal turn of an untreated control $H_{s f 1^{-1-}}$ mouse cochlea, showing a normal complement of outer hair cells. D: Representative phalloidin-stained surface preparation from the lower basal turn of an $H s f 1^{-1-}$ mouse cochlea 2 weeks after noise, showing a moderate loss of outer hair cells. $1,2,3$, rows of outer hair cells. Scale bars $=10 \mu \mathrm{m}$. 
Previous studies have shown that preconditioning the rodent cochlea with noise (Yoshida and Liberman, 2000; Niu and Canlon, 2002), restraint stress (Wang and Liberman, 2002), hypothermia (Henry and Chole, 1984), or heat shock (Yoshida et al., 1999) provides protection against a subsequent more damaging noise exposure that would normally result in permanent hearing loss. Rats or mice preconditioned with either a TTS noise known to induce Hsp70 (Altschuler et al., 1999) or a heat shock known to result in both up-regulation of Hsp70 (Yoshida et al., 1999) and activation of Hsf1 (Fairfield et al., 2002) exhibit $30-40 \mathrm{~dB}$ of protection against a subsequent more damaging noise exposure, if the noise exposure is given at a time when Hsp70 levels are maximal (Altschuler et al., 1999; Yoshida et al., 1999). These studies suggested a potential role for the heat shock response in cochlear protection. Our results support this by showing increased threshold shifts in mice lacking the Hsf1-dependent stress pathway.

In response to stress, Hsf1 induces the expression of a variety of genes involved in cellular protection and repair that may play a number of roles in the cochlea (for review see Fairfield et al., 2002; Trinklein et al., 2004). Molecular chaperones such as Hsp70 (Konishi et al., 1995), which is induced in the rat cochlea following noise (Lim et al., 1993), could prevent the aggregation of stress-denatured cochlear proteins and promote their proper refolding. Actin-associated proteins such as Hsp27 (Cooper et al., 2000), which is present in the outer hair cells and fibrocytes of the normal rat cochlea (Leonova et al., 2002), could promote the stabilization and repair of the actin cytoskeleton. In the cochlea, the actin cytoskeleton is particularly important not only for the function of hair cell stereocilia but also in the tension fibroblasts (fibrocytes) that anchor the basilar membrane to the spiral ligament. Free radical scavengers such as Hsp32 (heme oxygenase 1; Okinaga et al., 1996), which is induced in the rat cochlea following hyperthermia (Fairfield et al., 2004), could help to eliminate reactive oxygen species (ROS) generated by noise overstimulation, ischemia, and ototoxic drugs (Kopke et al., 1999). In addition, as a potent vasodilator, Hsp32 could also attenuate the localized capillary vasoconstriction that occurs in the stria vascularis following hyperthermia, noise overstimulation, and ischemia (Hawkins, 1971; Quirk et al., 1991). Activation of the Hsf1-dependent stress pathway may also prevent cochlear apoptosis both through the interaction of $\mathrm{Hsp} 27$ with cytochrome c (Bruey et al., 2000) and by the binding of Hsp70 (Beere et al., 2000; Saleh et al., 2000) and Hsp90 (Pandey et al., 2000) to apoptotic protease-activating factor 1 (Apaf-1), preventing assembly of the apoptosome complex and the activation of caspase-3. Hsf1 may also prevent cochlear inflammation in response to trauma and infection by inhibiting the activation of nuclear transcription factor kappa B (NFkB), an initiator of the inflammatory and apoptotic pathways (Malhotra and Wong, 2002).

In conclusion, the results presented here demonstrate that $H_{s} f 1^{-1-}$ mice, which lack Hsf1 protein and thus the
Hsf1-induced stress response, are unable to recover normal hearing sensitivity after exposure to a noise that produces only TTS in wild-type mice. $H s f 1^{-1-}$ mice also show outer hair cell loss and decreased cochlear recovery following noise overstimulation. These results suggest that the Hsf1dependent stress pathway plays an important role in cochlear recovery and repair after stress in the mouse cochlea.

\section{ACKNOWLEDGMENT}

We thank Ariane Kanicki for her assistance in dissecting mouse cochlea and preparing the phalloidinstained surface preparations in these studies.

\section{REFERENCES}

Altschuler RA, Miller JM, Raphael Y, Schacht J. 1999. Strategies for protection of the inner ear from noise induced hearing loss. In: Prasher DK, Canlon B, editors. Cochlear pharmacology and noise trauma. London: Noise Research Network Publications. p 98-112.

Beere HM, Wolf BB, Cain K, Mosser DD, Mahboubi A, Kuwana T, Tailor P, Morimoto RI, Cohen GM, Green DR. 2000. Heat-shock protein 70 inhibits apoptosis by preventing recruitment of procaspase- 9 to the Apaf- 1 apoptosome. Nat Cell Biol 2:469-475.

Bruey JM, Ducasse C, Bonniaud P, Ravagnan L, Susin SA, Diaz-Latoud C, Gurbuxani S, Arrigo AP, Kroemer G, Solary E, Garrido C. 2000. Hsp27 negatively regulates cell death by interacting with cytochrome c. Nat Cell Biol 2:645-652.

Christians E, Davis AA, Thomas SD, Benjamin IJ. 2000. Maternal effect of Hsf1 on reproductive success. Nature 407:693-694.

Cooper LF, Uoshima K, Guo Z. 2000. Transcriptional regulation involving the intronic heat shock element of the rat hsp27 gene. Biochim Biophys Acta 1490:348-354.

Dechesne CJ, Kim HN, Nowak TS Jr, Wenthold RJ. 1992. Expression of heat shock protein, HSP72, in the guinea pig and rat cochlea after hyperthermia: immunochemical and in situ hybridization analysis. Hear Res 59:195-204.

Fairfield DA, Kanicki AC, Lomax MI, Altschuler RA. 2002. Expression and localization of heat shock factor (Hsf) 1 in the rodent cochlea. Hear Res 173:109-118.

Fairfield DA, Kanicki AC, Lomax MI, Altschuler RA. 2004. Induction of heat shock protein 32 (Hsp32) in the rat cochlea following hyperthermia. Hear Res 188:1-11.

Hawkins JE Jr. 1971. The role of vasoconstriction in noise-induced hearing loss. Ann Otol Rhinol Laryngol 80:903-913.

Henry KR, Chole RA. 1984. Hypothermia protects the cochlea from noise damage. Hear Res 16:225-230.

Hutter MM, Sievers RE, Barbosa V, Wolfe CL. 1994. Heat-shock protein induction in rat hearts. A direct correlation between the amount of heat-shock protein induced and the degree of myocardial protection. Circulation 89:355-360.

Inouye S, Katsuki K, Izu H, Fujimoto M, Sugahara K, Yamada S, Shinkai Y, Oka Y, Katoh Y, Nakai A. 2003. Activation of heat shock genes is not necessary for protection by heat shock transcription factor 1 against cell death due to a single exposure to high temperatures. Mol Cell Biol 23:5882-5895

Konishi T, Nomoto M, Shimizu K, Abe T, Itoh H. 1995. Dominant role of the second heat shock element in expression of the HSP70-1 gene in rat liver after whole body hyperthermia. J Biochem (Tokyo) 118:10211029.

Kopke R, Allen KA, Henderson D, Hoffer M, Frenz D, Van de Water T. 1999. A radical demise. Toxins and trauma share common pathways in hair cell death. Ann N Y Acad Sci 884:171-191. 
Landry J, Chretien P, Lambert H, Hickey E, Weber LA. 1989. Heat shock resistance conferred by expression of the human HSP27 gene in rodent cells. J Cell Biol 109:7-15.

Leonova EV, Fairfield DA, Lomax MI, Altschuler RA. 2002. Constitutive expression of Hsp27 in the rat cochlea. Hear Res 163:61-70.

Lim HH, Jenkins OH, Myers MW, Miller JM, Altschuler RA. 1993. Detection of HSP 72 synthesis after acoustic overstimulation in rat cochlea. Hear Res 69:146-150.

Luft JC, Benjamin IJ, Mestril R, Dix DJ. 2001. Heat shock factor 1-mediated thermotolerance prevents cell death and results in G2/M cell cycle arrest. Cell Stress Chaperones 6:326-336.

Malhotra V, Wong HR. 2002. Interactions between the heat shock response and the nuclear factor-kappa B signaling pathway. Crit Care Med 30(Suppl 1):S89-S95

McMillan DR, Xiao X, Shao L, Graves K, Benjamin IJ. 1998. Targeted disruption of heat shock transcription factor 1 abolishes thermotolerance and protection against heat-inducible apoptosis. J Biol Chem 273:7523-7528.

Morimoto RI, Kline MP, Bimston DN, Cotto JJ. 1997. The heat-shock response: regulation and function of heat-shock proteins and molecular chaperones. Essays Biochem 32:17-29.

Myers MW, Quirk WS, Rizk SS, Miller JM, Altschuler RA. 1992. Expression of the major mammalian stress protein in the rat cochlea following transient ischemia. Laryngoscope 102:981-987.

Niu X, Canlon B. 2002. Protective mechanisms of sound conditioning. Adv Otorhinolaryngol 59:96-105.

Oh SH, Yu WS, Song BH, Lim D, Koo JW, Chang SO, Kim CS. 2000. Expression of heat shock protein 72 in rat cochlea with cisplatin-induced acute ototoxicity. Acta Otolaryngol 120:146-150.

Okinaga S, Takahashi K, Takeda K, Yoshizawa M, Fujita H, Sasaki H, Shibahara S. 1996. Regulation of human heme oxygenase-1 gene expression under thermal stress. Blood 87:5074-5084.

Pandey P, Saleh A, Nakazawa A, Kumar S, Srinivasula SM, Kumar V, Weichselbaum R, Nalin C, Alnemri ES, Kufe D, Kharbanda S. 2000. Negative regulation of cytochrome c-mediated oligomerization of Apaf-1 and activation of procaspase-9 by heat shock protein 90. EMBO J 19:4310-4322.

Quirk WS, Shapiro BD, Miller JM, Nuttall AL. 1991. Noise-induced changes in red blood cell velocity in lateral wall vessels of the rat cochlea. Hear Res 52:217-223.
Saleh A, Srinivasula SM, Balkir L, Robbins PD, Alnemri ES. 2000. Negative regulation of the Apaf-1 apoptosome by Hsp70. Nat Cell Biol 2:476-483.

Sha SH, Taylor R, Forge A, Schacht J. 2001. Differential vulnerability of basal and apical hair cells is based on intrinsic susceptibility to free radicals. Hear Res 155:1-8.

Sugahara K, Inouye S, Izu H, Katoh Y, Katsuki K, Takemoto T, Shimogori H, Yamashita H, Nakai A. 2003. Heat shock transcription factor HSF1 is required for survival of sensory hair cells against acoustic overexposure. Hear Res 182:88-96.

Trinklein ND, Murray JI, Hartman SJ, Botstein D, Myers RM. 2004. The role of heat shock transcription factor 1 in the genome-wide regulation of the mammalian heat shock response. Mol Biol Cell 15:1254-1261.

Wagstaff MJ, Smith J, Collaco-Moraes Y, de Belleroche JS, Voellmy R, Coffin RS, Latchman DS. 1998. Delivery of a constitutively active form of the heat shock factor using a virus vector protects neuronal cells from thermal or ischaemic stress but not from apoptosis. Eur J Neurosci 10:3343-3350.

Wang Y, Liberman MC. 2002. Restraint stress and protection from acoustic injury in mice. Hear Res 165:96-102.

Xia W, Vilaboa N, Martin JL, Mestril R, Guo Y, Voellmy R. 1999. Modulation of tolerance by mutant heat shock transcription factors. Cell Stress Chaperones 4:8-18.

Xiao X, Zuo X, Davis AA, McMillan DR, Curry BB, Richardson JA, Benjamin IJ. 1999. HSF1 is required for extra-embryonic development, postnatal growth and protection during inflammatory responses in mice. EMBO J 18:5943-5952.

Yoshida N, Liberman MC. 2000. Sound conditioning reduces noiseinduced permanent threshold shift in mice. Hear Res 148:213-219.

Yoshida N, Kristiansen A, Liberman MC. 1999. Heat stress and protection from permanent acoustic injury in mice. J Neurosci 19:1011610124.

Zhang Y, Huang L, Zhang J, Moskophidis D, Mivechi NF. 2002. Targeted disruption of hsf1 leads to lack of thermotolerance and defines tissuespecific regulation for stress-inducible Hsp molecular chaperones. J Cell Biochem 86:376-393. 